\title{
CARLOS DE OLIVEIRA E A RESPONSABILIDADE DO FALHANÇO
}

\author{
Leonardo Gandolfi \\ (Universidade Federal Fluminense)
}

\section{RESUMO}

Em Carlos de Oliveira, há a valorização de uma espécie de derrota corrosiva e geracional chamada, em certa altura, de "Falhanço", e que encontra paralelo, por exemplo, em outro grande neorrealista lato sensu como o cineasta italiano Visconti. Isso talvez possa aparecer na relação estrutural de dependência entre os textos do autor e o sistema cerceador ditatorial, como deixa ver o colapso do mundo em seus dois últimos livros, publicados após o 25 de Abril. Ou ainda o desencontro entre o compromisso neorrealista e o compromisso com uma memória pessoal que se desloca, num outro momento, para um desencontro entre voz (gesto) e escrita (registro).

PALAVRAS-CHAVE: Carlos de Oliveira, Neorrealismo, Falhanço.

\section{ABSTRACT}

Carlos de Oliveira is a portuguese author who writes a kind of corrosive and historic defeat that he called falhanço. In his books that concept can be compared to some movies of the lato sensu neo-realistic director Luchino Visconti. In Carlos de Oliveira books, the falhanço can appears in the structural relationship between his own texts and the censorship during Portugal dictatorship, as we can see in the collapse of world showed in his two last books, Pastoral and Finisterra, published after the redemocratization in 1974. This text discuss yet others implications of the falhanço's concept in his poems and fiction.

KEYWORDS: Carlos de Oliveira, Neorrealism, Falhanço. 
Conheci a obra de Carlos de Oliveira sob o signo de determinado construtivismo característico de um modo de interpretar a poesia moderna do século XX. Ou seja, índices de leitura como trabalho, rigor, precisão, apesar de modalizados, ganhavam destaque em qualquer aproximação da poesia do autor de Micropaisagem. Em parte foi o que fiz em minha dissertação a partir do livro $O$ aprendiz de feiticeiro. No entanto, em meio ao que já tinha sido feito, algo de outra cor, ao menos para mim, aparecia entre aquelas páginas do livro de 1972. Em um texto chamado "O iceberg" (OLIVEIRA, 2004, p. 163-177), o autor nomeou o que viria a ser um conceito - embora careça muito ainda de conceituação - que motivaria em grande parte meu trabalho de doutoramento em curso. Justamente por estar em curso, o conceito de "falhanço" ainda oferece mais dúvidas que certezas, mais disposição ao erro que ao acerto, enfim, mais extravios que rigores.

Como posso em um poeta construtivista - daí minha aproximação na pesquisa de doutorado entre ele e João Cabral de Melo Neto ${ }^{1}$ - valorizar o que, ao invés de construir, destrói. Talvez se trate mais de corrosão, derrota, do que propriamente de destruição. Carlos de Oliveira está um pouco distante de uma atitude iconoclasta vanguardista que, no desejo de destruir, sempre acaba revelando alguma propensão ao heroísmo, mesmo pela negativa. Não, o falhanço não comporta heroísmos, uma das poucas certezas que ao fim um autor como Carlos de Oliveira proferiria seria a certeza das tentativas que levam ao erro e é errando que se avança, mesmo que em espiral, porque errar, como diz o ditado, é humano. E poucos autores portugueses do século XX foram tão atentos ao humano como Carlos de Oliveira o foi. Porque se a arte em si é humana, é claro, a dele, digamos, fez desse tópico o seu próprio material de trabalho ao levar ao extremo os limites, se eles existirem, entre aspectos formais e texualizantes da literatura e um caráter mais imediato e intervencionista desta mesma.

Tornou-se então uma insistência minha e agora uma espécie padrão de trabalho dar a ver o erro e, mais ainda, procurar situá-lo como um modo de ler determinada literatura, evitando o desejar convertê-lo em um operador de leitura que corte arestas, amortize suas forças - por assim dizer - erráticas, para convertê-las em apropriações domesticadas dos poemas e de alguma ficção do autor. No entanto há o risco, porque é sempre mais conveniente andar por caminhos seguros cujo final já supomos. Optar pelo erro, pela falha, implica talvez estar aberto a surpresas, mesmo que desagradáveis, como por exemplo a possibilidade de um dos sentidos de determinado acento importante de sua obra dialogar tão diretamente com os mecanismos cerceadores da censura portuguesa. Quando tais mecanismos mudam de registro - digo isso após o 25 de Abril -, parte do sistema de nomeação de mundo segundo Carlos de Oliveira entra em franco colapso, como deixam ver os dois últimos livros do autor, Pastoral e Finisterra - paisagem e povoamento, respectivamente publicados em 1976 e 1978. As transformações em sua obra de 1942 até 1978, inclusive a dinâmica da reescrita, como mostrarei mais adiante, se deram devido a um diálogo não-imediato, mas estrutural com a censura, i.e., a melhor maneira de combatê-la foi assimilando seus mecanismos de cerceamento através da reescrita, entre outros recursos. Seus últimos dois livros, entre outras coisas, falam mais da falência de um sistema de significação que perdeu ou está em vias de perder seu referencial. Não à toa, Finisterra tornou-se 
exemplar no panorama da narrativa portuguesa justamente pela radicalidade com que anuncia uma outra cena a que falta - podemos dizer - tudo, menos o efeito vertical de leitura pelo qual os grandes textos continuam a ser conhecidos.

Para além disso, o erro, ou o falhanço, pode se tornar perspectiva em certo momento de um neorrealismo, cuja visão será fatalmente trágica segundo Eduardo Lourenço (1983, p. 141-202). Adiar a beleza ou, pior, determinado tipo de subjetividade, em prol das cidades futuras, como disse o autor em Terra da Harmonia: "Cantar" um canto de intervenção ou simplesmente cantar o que quer que seja em fins da década de 40 em Portugal "é empurrar o tempo ao encontro das cidades futuras/ embora fique mais breve a nossa vida" (OLIVEIRA, 1982, p. 55). Sendo este, na íntegra, o primeiro poema desta terra da harmonia, vê-se que se trata de uma harmonia muito curiosa em que, mais que o canto e um tempo utópico e adiado, o que fica é a brevidade da nossa vida: ars longa vita brevis ou, já a visão desencantada e desestetizante de um Camões, "Pera tão longo amor tão curta a vida" (CAMÕES, 1981, p. 235). A perspectiva neorrealista em Carlos de Oliveira, primeiro, é um embate entre o compromisso com uma memória, digamos, pessoal e o compromisso com uma realidade social, pactos esses que, no entanto, não deveriam estar em conflito, mas que estão graças às circunstâncias históricas. Mais tarde tal tensão ganha mais espessura quando as imagens se deslocam na passagem do canto à caligrafia. Ao invés de uma palavra que espalha devido ao poder e conteúdo da voz que a canta, a caligrafia é silenciosa e minuciosa, nela há espaço para outro tipo de falha que, como sabemos, é a separação entre palavra e corpo. Perdida a voz, fica a palavra destituída de gesto físico: "cada poema,/ no seu perfil/ incerto/ e caligráfico,/ já sonha/ outra forma” (OLIVEIRA, 1982, p. 99). O voltar-se do poema para sua própria materialidade - procedimento tão caro a certo Carlos de Oliveira, sobretudo nos anos 60 - é uma forma de compensar a perda da voz e recuperar uma dimensão física do gesto textual.

No entanto, a memória que chamei de pessoal continua a não encontrar na escrita e no tempo do poema uma representação fidedigna nos moldes que Oliveira desejou. Daí sua insistência em um hiper-realismo, também de linguagem, que, por um tempo, encontra frágil equilíbrio num tipo de nanorrealismo facilmente extraviável, visível no livro Micropaisagem, e finda em Entre Duas Memórias, livro de 1971 em que o tempo explode no intermédio da produção do texto e de sua recepção com o leitor. O que resta, caligráfica e silenciosamente, são elementos soltos da paisagem arruinada da infância e do poema: "xisto, sílica, trazidos/ de minas profundíssimas; e nele a cinza à espera/ do vento árido, sem pólen,/ que fende o céu/ esterilmente: cálice vazio; / ou cheio de silêncio; mas/ cálice, cristal." (OLIVEIRA, 1982, p. 150).

É comum entre neorrealistas o recurso da metalinguagem. $\mathrm{Na}$ década de 40 do cinema italiano, tanto Rosselini - na trilogia da guerra - quanto Visconti em A Terra Treme abusam de recursos até então muito comuns na linguagem cinematográfica documental. O modo como eles utilizam na narrativa tais recursos formais - como a locação, movimento e enquadramento da câmera, certo naturalismo nas atuações - faz com que repensemos o lugar da narrativa e do documentário ao mesmo tempo. $\mathrm{Na}$ verdade, a presença de certos elementos da sintaxe do documentário no cinema de ficção chama nossa atenção para a materialidade da linguagem 
cinematográfica, como poucas vezes vimos. Em relação a isso e a outros pontos, acho muito proveitosa a aproximação entre a obra de Carlos de Oliveira e determinado cinema neorrealista para assim tentar entender, para além dos textos, mas sem nunca excluí-los, certa dimensão do neorrealismo como visão de mundo. Por isso, mais à frente retorno a essa relação para, a partir dela, suscitar alguns problemas. Retornando ao ponto da metalinguagem, ainda dentro de uma perspectiva de engajamento deliberado e de intervenção na realidade social, em determinado momento do século XX houve uma pedagogia da arte, de fundo, por assim dizer, metalinguístico. Podemos vê-la em certa literatura dramática que passa por Artaud e é muito bem professada por um autor como Bertolt Brecht:

Mostrem que mostram! Entre todas as diferentes atitudes Que vocês mostram, ao mostrar como os homens se portam

Não devem esquecer a atitude de mostrar.

A atitude de mostrar deve ser a base de todas as atitudes

(...) O seu mostrar conservará a atitude de mostrar

De pôr a nu o já disposto, de concluir

De sempre prosseguir. Então mostram

Que o que mostram, toda noite mostram, já mostraram muito

E a sua atuação ganha algo do fazer do tecelão, algo

Artesanal. E também algo do próprio mostrar (...) (BRECHT, 1986, p. 244)

Ou seja, a arte engajada comporta em tal pedagogia a exposição da sua estrutura, oferecendo uma visão que deseja ser sem maquiagem, franca e honesta do objeto estético, que não pode enganar ninguém no que faz, ao contrário, ela revela todas as suas finalidades só em aparecer. $\mathrm{Na}$ prática, o palco jamais se esconderia em meio a cenários: seria ele mesmo o palco parte integrante do cenário e, no limite da tal metalinguagem, a peça representaria a si mesma apenas como peça, assim revelando um tipo de realismo outro que não esconde suas vigas e tijolos. Tal conceito atinge a arquitetura - a tão desejada união moderna de arte e vida - e também, como sabemos, a literatura, em especial a poesia. Os versos de que Carlos de Oliveira é capaz são devedores dessa visão pedagógica de mostrar-se mostrando. Mas não a cumpre totalmente e isso é o que acontece - em maior escala - nos livros publicados pelo autor após o 25 de Abril, Pastoral e Finisterra. Entre outros erros de Carlos de Oliveira, está o falhanço da metalinguagem que ao mesmo tempo é o falhanço da pedagogia da literatura - ainda que reeelaborada - e também o falhanço do poema como coisa autônoma e atuante.

Recupero o texto "O iceberg" em que o autor cita o falhanço, conceito ambíguo, pois, no extravio, também sugere uma produtividade frágil que terá a ver ainda com a vida - vita brevis - presente no brevíssimo poema citado acima sobre as cidades futuras: “(...) todo o escritor português marginalizado sofre biograficamente do que posso denominar complexo do iceberg: um terço visível, dois terços debaixo d'água." (OLIVEIRA, 2004, p. 163)

Para além e ao mesmo tempo em consonância formal com a repressão e censura de um governo ditatorial, o que o autor escreve no trecho anterior terá a ver com a memória pessoal, sendo sacrificada em prol de 
um canto geral, trágico e falhado. E terá a ver ainda com o sacrifício da voz e do corpo em prol do silêncio e da autonomia precária da caligrafia.

$\mathrm{O}$ iceberg afundou mais uns bons centímetros. Esta acumulação de dados negativos transformou-nos a existência naquilo a que os franceses gostam de chamar a travessia do deserto (...). Os factos abonam pouco a seu favor [do escritor] e as datas são para esquecer" (OLIVEIRA, 2004, p. 164)

Virá desse naufrágio lento e gradual - e por isso mesmo significativo, porque ele não naufraga sozinho - a força com que seus textos emergem. Em nome da liberdade, mesmo que seja a liberdade para errar - "Errei todo o discurso dos meus anos" (CAMÕES, 1981, p. 341) -, surge uma alegria difícil, porque é fruto da responsabilidade de estar no mundo:

Longe de mim a ideia de simular que noutras circunstâncias me caberia uma riqueza biográfica excepcional. Não senhor. Digo apenas que tinha direito à experiência da minha própria liberdade. (...) Veríamos depois o que sairia dessa experiência. Talvez nada. Mas então, que alegria triste assumir como última consequência de ser livre a responsabilidade do falhanço. (OLIVEIRA, 2004, p. 164)

\section{2.}

Por falar em liberdade, a principal razão pela qual Oliveira menciona o "falhanço" diz respeito ao fato de que a alguns escritores portugueses do século XX não foi dado o direito de terem biografia: “(...) todo o escritor português marginalizado sofre biograficamente do que posso denominar complexo do iceberg: um terço visível, dois terços debaixo d'água" (OLIVEIRA, 2004, p. 163). A censura está não só no centro do neorrealismo, mas também no centro da ruptura de Oliveira com o movimento, sua reinterpretação dele. Porque, por um lado, a partir de certo momento, não há neorrealismo, em última instância, se não houver censura. Por outro, seu desligamento do partido comunista se deu pela tentativa constante de intervenção do mesmo partido nos textos que figurariam no livro Cantata de 1960. Ou seja, tanto antes quanto depois de um engajamento stricto sensu no neorrealismo, a dinâmica da censura é fundamental para sua obra: tanto que a partir dos anos 50 e 60, anos pós-partido, ele a incorpora, redimensionando-a como reescrita. Abro um parêntesis: a primeira vez que Carlos de Oliveira reescreveu um livro aconteceu em 1944, por ocasião da apreensão do romance Alcatéia. A segunda e última edição do livro é o primeiro livro a ser reescrito pelo autor, não por vontade própria, mas por imposição da censura. Tal procedimento Carlos de Oliveira incorporaria a seu trabalho como forma realista-estrutural de falar de uma realidade portuguesa cerceadora, porque a reescrita emula os procedimentos da censura para criticá-la.

Tanto neste momento quanto em um anterior de franca denúncia da ditadura, Oliveira se valeu de projetos utópicos, seja para tornar o mundo ou Portugal um lugar melhor, seja para fazer com que a linguagem, a partir de um movimento de descrição interna de si mesma, consiga dizer o mundo - configurando assim dois momentos na obra do autor. No entanto, há restrições no que diz respeito a tal divisão, porque, quando vistos de 
perto, percebe-se que tais textos não deixam de ser neorrealistas, no sentido da intervenção, nem deixam de ter uma perspectiva textualista, mesmo nos primeiros livros: "Hei-de cantar-vos a beleza um dia,/ quando a luz que não nego abrir o escuro/ da noite que nos cerca como um muro,/ e chegares a teus, reinos, alegria" (OLIVEIRA, 1982, p. 21). De fato, embora use mecanismos mais ou menos diferentes dependendo da época, o texto de Oliveira, primeiro, é utópico, e, segundo, relaciona-se estreitamente com a parte submersa do iceberg cuja imagem da censura representa-o tão bem.

$\mathrm{O}$ que acontece quando oficialmente a censura em Portugal perde alguma força e o projeto utópico de Carlos de Oliveira já não tem mais onde se alimentar? Um início de possível resposta está no trecho já citado de "O iceberg": "O iceberg afundou mais uns bons centímetros. (...) Os factos abonam pouco a seu favor e as datas são para esquecer" (OLIVEIRA, 2004, p. 164). E se o iceberg afundar cada vez mais e mais até haver parte emersa apenas para não se extinguir a vida?

A narrativa de Finisterra - paisagem e povoamento foi publicada em 1978, quatro anos e alguns meses após o 25 de Abril. Não que as datas exatas sejam tão importantes assim para Carlos de Oliveira; o autor de Entre Duas Memórias acreditava mais na espessura de um tempo que indiferenciasse passado, presente e futuro, corroendo já aquele apelo utópico que eu disse representar, a partir de uma perspectiva, sua obra. A corrosão em Oliveira está presente desde o início, mas vem com toda força mesmo a partir de Micropaisagem de 1969, do citado Entre dias Memórias de 1971 e do potpourri em prosa que é O Aprendiz de Feiticeiro, de 1972, para culminar enfim na representação social do 25 de Abril que foram seus dois últimos livros.

De novo "O Iceberg": "Os factos abonam pouco (...) e as datas são para esquecer", chamemos a isso de "a travessia do deserto". Porque, se o projeto utópico de Oliveira não estava ligado exclusivamente a um lugar no futuro, ele tinha como tônica um desejo intenso de mobilidade espacial de tempos, representado muito bem, por exemplo, ao longo do poema "Estalactite" de Micropaisagem. E tal mobilidade, parece, paradoxalmente perde determinado tipo de força depois do início do processo de redemocratização e emerge mais radical ainda:

Osso de baleia, textura de madeira pobre, exposta á água, à erosão, sem apodrecer: a luz, quando bate de frente nos veios foscos, desprende uma poalha cor de cinza, quase a reacender-se. A densidade calcária decresce tanto que ambos podem flutuar (a criança e o osso da baleia) sobre murgos biliosos, caules de gisandra, líquenes, doenças vagarosas. (OLIVEIRA, 1978, p. 3-4)

Finisterra - paisagem e povoamento leva ao limite os sentidos de uma narrativa, evidencia seus matérias e expõe a fragilidade, tanto a do autor ao escrevê-la, como a nossa ao lê-la. Se houvesse uma história que pudesse ser narrada seria a da criança e do homem, cada qual ao seu momento, que preparam o desenho da casa e sua maquete. A casa em si também comparece à narrativa, como coisa fantasmagórica, presente e ausente por uma memória material que se resume a restos ou a materiais antes da construção. Ambos, criança e homem, muitas vezes indistintos, tocam seus projetos, cada um à sua maneira, mas desde o início sabemos que a única 
casa possível é a do livro e mesmo essa resume-se ao amontoado de restos, escombros de um projeto que ficou distante de se formar, mas que paradoxalmente buscava modelo em algo que existiu na memória ${ }^{2}$. Espelha-se aí o próprio percurso do escritor: Finisterra é a duplicata de Casa na Duna e ao mesmo tempo sua destruição. A parte visível do iceberg é o osso da baleia, coisa marítima que curiosamente não apodrece, porque já se integrou à natureza ríspida de uma pontecializada Gândara, "cinza”, biliosa e de "doenças vagarosas".

Dois anos antes de Finisterra, Carlos de Oliveira publica seu último e mínimo conjunto de poemas de nome Pastoral, grupo de textos que encerra o segundo volume dos poemas reunidos do autor. Só um ano depois, o mini-livro é transformado em plaquete não comercial para ser distribuída a amigos. São dez poemas que em parte retornam ao formato mínimo de Cantata, publicado vinte anos antes, e em parte antecipam a franca corrosão de sentido de Finisterra. Em Pastoral, o campo semântico ligado à terra, já forte em toda a obra, amplia-se ainda mais e aponta para o desmantelar dos objetos e da própria natureza.

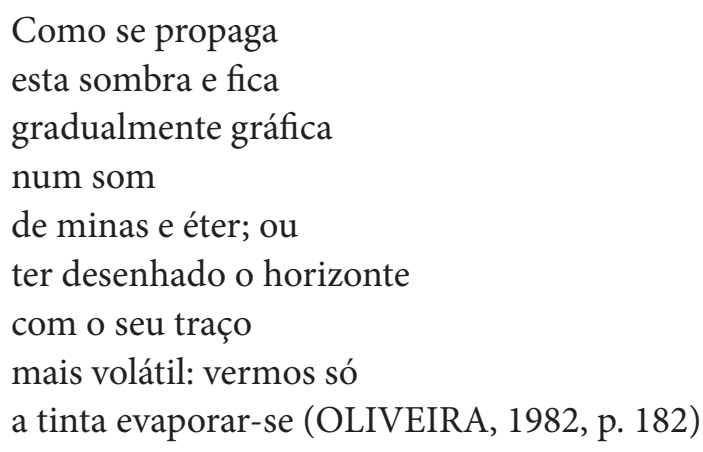

No caso, esse é um dos poucos poemas onde de fato a corrosão é tematizada; nos demais, funciona como amostra daquilo sobre o qual se fala, ou seja, literalmente acompanhamos a evaporação das palavras ao serem lidas e a impressão que fica é de que estamos diante de um mundo limítrofe, no qual passamos gradualmente do lado mais ordenado para o outro, o do caos. Um dos textos chama-se "Dente" e mostra que o discurso que Oliveira está desaparelhando não é apenas o da memória pessoal, reduzida à paisagem gandarense, seu poder de expansão - como em livros anteriores, mas com outra perspectiva - atinge uma espessura histórica, que pode levar o leitor a sobrepor Pastoral a Portugal:

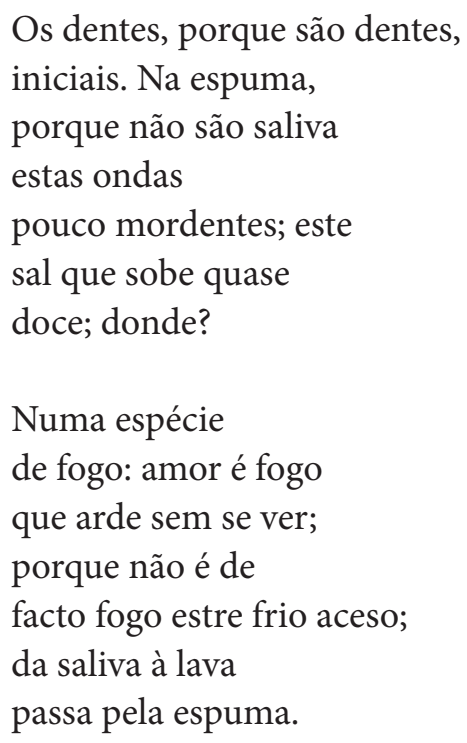


Só os dentes.

duros, ácidos, concentram-se

tacteando signos sempre moventes

de fúria. Mordida

a pele cintila; espelho

dos dentes, do seu esmalte voraz;

suavemente. (OLIVEIRA, 1982, p. 187-188)

Em relação ao fero amor, nada mais próprio que isolar os dentes e convertê-lo em algo tão próximo da paisagem ossificada - regresso à matéria básica das coisas, tão caro ao autor. Do dente ao cálcio, até o sal e então até a cal das dunas, também jogada sobre os mortos para, mais rápido, se decomporem. Este Camões é já um Camões via Carlos de Oliveira em que o amor ardente não se inscreve efetivamente nem se fixa, porque está sujeito ao corpo e o corpo é um "frio aceso", "sal que sobe quase/ doce", "éter" "com o seu traço mais volátil". Por falar em erro camoniano, repito as palavras de Oliveira em "O iceberg":

Longe de mim a ideia de simular que noutras circunstâncias me caberia uma riqueza biográfica excepcional. Não senhor. Digo apenas que tinha direito à experiência da minha própria liberdade. (...) Veríamos depois o que sairia dessa experiência. Talvez nada. Mas então, que alegria triste assumir como última consequência de ser livre a responsabilidade do falhanço. (OLIVEIRA, 2004, p. 164)

A discutida metáfora do iceberg - para além de ligar o falhanço a certa tradição lírica portuguesa que se inscreve com o verso-súmula "Errei todo o discurso dos meus anos" - pode abrir duas frentes em meu trabalho: 1) o falhanço como consequência final tanto da tentativa de Carlos de Oliveira intervir na realidade através do neorrealismo, quanto da também tentativa utópica e posterior de intervir na realidade do mundo através da realidade da linguagem; 2) o último falhanço desta obra como sendo a emersão total do iceberg que é o mesmo que sua submersão completa e que tem como fator determinante a liberdade. Ou seja, a ausência de aparelhos despóticos de controle social desautoriza os textos de Carlos de Oliveira em relação aos seus próprios mecanismos de produção de sentido, criados em função daqueles aparelhos.

Em outras palavras, o processo histórico português que culmina no 25 de abril de 1974 desencadeia na obra de Carlos de Oliveira o fim da fricção que seus versos a tanto custo aprenderam a criar. E seus dois últimos livros testemunham tal processo de amortização de forças e do desejo e o silenciamento diante de outras realidades para as quais sua obra está completamente desarmada, a sabê-las: indiferença e morte, que nunca precisaram de ditadura alguma para existir: "que alegria triste assumir como última consequência de ser livre a responsabilidade do falhanço”. Diante dos problemas, curiosamente, a ditadura alimentava no discurso contrário a ela uma utopia, que se torna distópica quando essa mesma ditadura acaba, mas os problemas não. Daí que se fale que, sobretudo, Finisterra seja representação de um fim da história ou ainda "a história de um mundo que assiste ao seu próprio colapso" (MARTELO, 1998, p. 182). A história pode não terminar, mas por certo muda de direção. Só não é possível saber se essas outras direções nos levam por caminhos tão diferentes assim. 
3.

Retornando à questão do neorrealismo e suas implicações em relação ao falhanço na obra de Carlos de Oliveira, para terminar comparo rapidamente um poema de Turismo, publicado em 1942, mas em versão reescrita de fins da década de 50, versão que substitui a anterior - e um poema de Pastoral. Um texto do primeiro livro e um do último. No entanto, sem esquecer que em Carlos de Oliveira, o procedimento da reescrita também combate um visão cronológica-evolutiva, central para que eu perceba aquele espessura de tempo já mencionada. Tal leitura tem como fim as aproximações dos textos de Oliveira e o cinema neorrealista. No caso, o cotejamento das fitas inicias de Visconti e Rosselini e as últimas, já da década de 70, realizadas pelos mesmos diretores. Essa segunda comparação lança mão, é claro, de instrumentos diferentes dos utilizados na primeira, já que meu objeto não é exatamente as relações interartes, mas sim algumas linhas de força do neorrealismo português redimensionadas por Carlos de Oliveira, ao longo dos anos, tanto por meio da reescrita, quanto através dos caminhos para os quais, como vimos, seus dois últimos livros apontam: a já mencionada coletânea de poemas Pastoral, de certa maneira um duplo de Portugal pós-idílico, e a narrativa Finisterra - paisagem e povoamento, espécie de lugar limítrofe português onde simbólico e não-simbólico gradativamente se sobrepõem.

O poema de Pastoral chama-se "Registo", transcrevo-o na íntegra:

\author{
Saber que seja \\ este hálito: se terra \\ ou ar movido \\ já por metais mutáveis \\ na linha das colinas.
}

\author{
Como se propaga \\ esta sombra e fica \\ gradualmente gráfica \\ num som \\ de minas e éter; ou \\ ter desenhado o horizonte \\ com o seu traço \\ mais volátil: vermos só \\ a tinta evaporar-se.
}

Não há outro

registro, mas alíneas

deste. Assim flutua;

cálculo e acaso; a cal

ainda tensa das casas

sobre

o crepúsculo esponjoso. (OLIVEIRA, 1982, p. 182)

É natural nos atermos inicialmente às imagens metapoéticas, porque, em meio às outras, estas são mais identificáveis em termos de poesia moderna e poesia moderna portuguesa: o "traço" mais volátil, mais incerto, tanto que só de aparecer já começa a se evaporar a tinta que o representa. Assim também os sentidos do poema inscrevem-se para serem 
já outra coisa, como já dizia um poema de Oliveira publicado 1968 e já citado: "cada poema,/ no seu perfil/ incerto e caligráfico,/ já sonha/ outra forma" (OLIVEIRA, 1982, p. 99). Como não poderia deixar de ser, destaco no poema seus elementos de paisagem ou de "alíneas" de paisagem como dizem os versos. Alíneas são as subdivisões de um artigo ou documento, por exemplo, em a), b), c) etc. Não sabemos se o "hálito" mencionado vem da "terra" ou do "ar movido por metais mutáveis nas linhas das colinas", pode ser que venha dos dois. É nesse mesmo hálito, vindo da terra e de um ar-metal-mutável nas colinas, que "flutua" levemente "a cal/ ainda tensa das casas". Tudo isso sobre uma paisagem cujo crepúsculo é esponjoso. O excesso de adjetivação perturba, "esponjoso", "tensa", "mutável", "volátil", tornando - como avisam esses mesmos adjetivos - as coisas realmente incertas aos olhos do leitor: mesmo lentamente, ele parece não ter tempo para assimilar tantas novas qualidades. Então o que sabemos é que instavelmente há "terra", "ar", "colinas", "crepúsculo" e "casas", elementos, alíneas de uma paisagem prestes a evaporar ou já evaporada. Isso para não falar do "cálculo" e do "acaso" regendo tais imagens. E se há "cálculo" podemos crer que parte dessa instabilidade estava programada, no entanto há o "acaso". Poderíamos reformular a questão dessa forma: tudo surpreende, embora tudo já estivesse programado.

Agora um poema de Turismo, o primeiro, chamado "Infância":

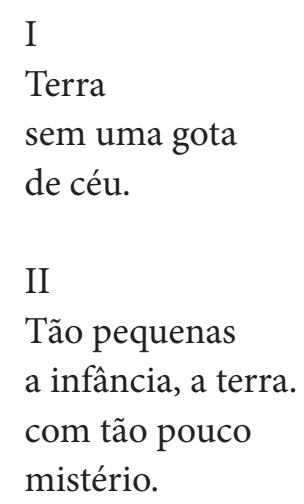

Tão pequenas a infância, a terra. com tão pouco mistério.

Chamo às estrelas rosas.

E a terra, a infância, crescem no seu jardim aéreo.

III

Transmutação

do sol em oiro.

Cai em gotas, das folhas, a manhã deslumbrada.

IV

Chamo

a cada ramo 
de árvore

uma asa.

E as árvores voam.

Mas tornam-se mais fundas

as raízes da casa,

mais densa

a terra sobre a infância.

É o outro lado

da magia.

V

E a nuvem

no céu a tantas horas,

água suspensa

porque eu quis,

desmorona-se e cai.

Caem com ela

as árvores voadoras.

VI

Céu

sem uma gota

de terra. (OLIVEIRA, 1982, p. 3)

Gostaria logo de chamar atenção para o ato de nomeação que, no poema anterior, aparecia, noutra clave, através da tinta a evaporar-se. "Chamo às estrelas/ rosas", "Chamo/ a cada ramo/ de árvore/ uma asa". A adjetivação, ao contrário, em "Infância", não perturba como em "Registo", ela serve sobretudo para fixar uma paisagem não só de "terra", mas "de ar movido": "jardim aéreo", "água suspensa", "árvores voadoras". E tal paisagem entre céu e terra com "nuvem", "rosas", "árvore" e finalmente "casa" lembra de longe a do outro poema com "crepúsculo", "colinas" e "casa". Em "Infância" há um movimento que será o mesmo do poema "Estalactite" das gotas que caem e caem até confundir movimento com imobilização a pedra que é a estalactite de fato. No entanto, em "Infância" há também um movimento vertical em sentido contrário que é o de elevação, pois "as árvores voam" e só porque voam é que "tornam-se mais fundas/ as raízes da casa" e mais "densa" e "tensa" a "terra sobre a infância". Lembro da "cal ainda tensa das casas sobre o crepúsculo esponjoso". As "casas" em "Registo" como a "casa" em "Infância" se inscrevem através de um movimento vertical que por fim em "Registo" é a "tinta a evaporar-se". Entre os poemas há uma continuidade sem haver, é claro, evolução; as imagens são recorrentes, circulares, repetem-se com variações em espiral que as deslocam, mas eu não sei em quais direções. Sei, no entanto, que em "Infância" há uma consciência maior da queda e em "Registo" da não inscrição, da volatilidade, do desaparecimento. Nos dois poemas, através do movimento vertical, entre a queda de um e a evaporação de outro, o que se inscreve é a morte. O "crepúsculo" dá conta disso e a "terra sobre a infância" também. Os dois poemas tematizam a nomeação de um mundo em crise, sem bem que crise de diferentes naturezas, a natureza do que cai e a natureza do que se evapora. 
Roberto Rosselini dirigiu três narrativas matrizes para o neorrealismo, que ultrapassaram não só o contexto italiano, como o contexto do próprio cinema: na década de 40, a trilogia da guerra com Roma, cidade aberta, Paisá e Alemanha ano zero. Já pelos títulos topológicos, pode-se perceber o diálogo com a paisagem: em todos eles o lugar ou a destruição do cenário - todos não-cenários de caráter documental - não é exatamente determinista sobre os personagens, mas ele - o processo de formação da paisagem nos filmes torna-se protagonista das ações. Com a diluição da estética neorrealista e sua aproximação da atriz Ingrid Bergman, Rosselini muda o foco e, tempo depois - de fins da década de sessenta para setenta -, vai-se concentrando na TV com produções de fins pedagógicos que visavam biografar grandes nomes da história do pensamento como Sócrates, Pascal, Decartes e São Francisco. Observando rapidamente, Rosselini muda de instrumental mais do que de finalidade, porque se os filmes iniciais eram marcantes pela inovação de linguagem, sempre em diálogo com o documentário e pela perspectiva de denúncia, os seriados de TV abandonam a paisagem, mudam o tom experimental e documental por trabalho realmente de maior alcance, acreditando na exemplaridade das biografias. Não sei dizer, no entanto, se essa perspectiva mais otimista terá funcionado: se na Itália à época terá surtido algum efeito considerável, porque fora dela não surtiu, retornando ao que Eduardo Lourenço chamou em Carlos de Oliveira de caráter trágico do neorrealismo, i.e., o sacrifício da perspectiva individual em prol de um coletivo sempre porvir e sempre adiado.

Em termos de cinema, o exemplo de Visconti talvez ajude mais na minha leitura do falhanço - que nos poemas lidos aparece por meio da queda e da evaporação - também como caráter neorrealista em Carlos de Oliveira. A perspectiva derrotista social de A Terra Treme de 1948 se transfigura e ganha maior espessura em fitas posteriores como Rocco e seus irmãos de 1960 e O Leopardo de 1963, ampliando significativamente com Morte em Veneza de 1971 e Violência e Paixão de 1974 em que se pode ver a derrota do desejo, seja através da arte como na adaptação da novela de Thomas Mann, seja através da família como no filme de 74. Em Violência e Paixão, o solitário e desencantado professor e colecionador de arte - arquétipo do intelectual que se isolou com o passar do tempo -, interpretado por Burt Lancaster, é perturbado pelos novos valores da estranha família da qual se torna vizinho. A visão de Visconti é profundamente desiludida; embora mude, ela não evolui necessária e cronologicamente. Carlos de Oliveira muda: da queda até a evaporação infinita no poema. E Visconti também: de explorados pescadores para um compositor ou uma marquesa, como a interpretada por Silvana Mangano em Violência e Paixão; todos têm na derrota pessoal ou coletiva sua perspectiva.

A aproximação com o cinema serve para tentar entender qual a direção das metamorfoses ocorridas no interior da obra de Carlos de Oliveira. Que ela tenha se transformado isso é certo, só não me parece tão certo assim que tenha perdido algumas das principais características que fizeram dela um texto neorrealista em lato sensu. O último Carlos de Oliveira não é outro Carlos de Oliveira. Finisterra retoma Casa na Duna, Pastoral retoma Turismo e Cantata, ajudando a configurar a tal espessura de tempo da qual a reescrita é protagonista. Finisterra e Pastoral dialogam porque ambos livros, com títulos topológicos, fazem do Portugal combativo e em queda um Portugal pós-25 de Abril e sem ditadura evaporar-se. Para além 
do "tema" da terra, se assim pode-se falar nesse livro, as 8 letras da palavra Pastoral repõem as 8 letras da palavra Portugal, regressando a uma noção pré-romântica de paisagem. Finisterra era o nome dado às futuras terras de Portugal durante parte do império romano, porque era lá que ele conhecia de fato seu fim, pelo menos o geográfico. A casa em Pastoral e, sobretudo, em Finisterra também é a casa portuguesa conhecendo seu fim - fim contínuo que não termina pelo menos enquanto durar a leitura.

\section{4.}

O percurso que fiz serviu para mostrar, entre outras coisas, como a noção de tempo e memória em Carlos de Oliveira - traço fundamental em seus livros - ou ainda a perspectiva neorrealista - aliás, diretamente relacionada ao mesmo tempo e memória - estão ligadas a uma derrota produtiva que, como vimos, o autor chamou de falhanço. O que - é bem possível - não o determine como sendo necessariamente um autor pessimista, porque às vezes acontece de o otimismo vir de onde menos se espera. Parece ser uma tônica, em sua obra, um tipo de extravio que o impediu de ser, por exemplo, mais um autor neorrealista ou ainda o entusiasta de uma noção textualizante de literatura. Quando hesito entre palavras como "falhanço", "erro", "derrota" e agora "extravio", estou apenas me esforçando para nomear algo em seus livros que nunca deixou de fora o sujeito.

\section{NOTAS}

1 A pesquisa trata de alguns diálogos entre a formação da subjetividade e a paisagem nos textos de Carlos de Oliveira e a poesia de João Cabral de Melo Neto.

2 Cacaso, no livro Grupo Escolar, escreve em "Poema” o seguinte: “Trago comigo um retrato / que me carrega com ele bem antes / de o possuir bem depois e de o ter perdido. // Toda felicidade é memória e projeto" (Cacaso, 1985, p.116). Contemporâneo de Finisterra (Grupo Escolar é de 1974), o texto de Cacaso poderia ser uma leitura performática do texto de Oliveira. Tanto pela atividade e passividade do sujeito - ele traz um retrato e é carregado por ele -, quanto pela acumulação e indiferenciação de tempos - a ação acontece antes de ele possuir o retrato e também depois de ele o perder. Por fim, o verso final parece ser uma súmula envolvendo as palavras "felicidade", "projeto" e "memória". O que fica claro é que ela, a felicidade ou algo afim, talvez seja incompatível com o presente, como já víramos no poema das cidades futuras de Terra da Harmonia.

\section{REFERÊNCIAS BIBLIOGRÁFICAS}

BRECHT, Bertolt. Poemas 1913-1956. Seleção e tradução de Paulo César Souza. São Paulo, Editora Brasiliense, 1986.

CACASO. Beijo na Boca e outros poemas. São Paulo: Brasiliense, 1985.

CAMÕES, Luís de. Redondilhas, canções e sonetos. Rio de Janeiro: Real Gabinete Português de Leitura, 1981.

LOURENÇO, Eduardo. Sentido e Forma da Poesia Neo-Realista. $2^{\circ} \mathrm{ed}$. Lisboa, Publicações Dom Quixote, 1983.

MARTELO, Rosa Maria. Carlos de Oliveira e a referência em poesia. Porto: Campo das Letras, 1998. 
OLIVEIRA, Carlos de. O Aprendiz de Feiticeiro. Lisboa. Assírio \& Alvim, 2004.

. Finisterra - paisagem e povoamento. Lisboa: Sá da Costa, 1978.

Trabalho Poético (poesia reunida). Lisboa, Sá da Costa Editores, 1982.

(Recebido para publicação em 18/11/2010

Aprovado em 16/12/2010) 